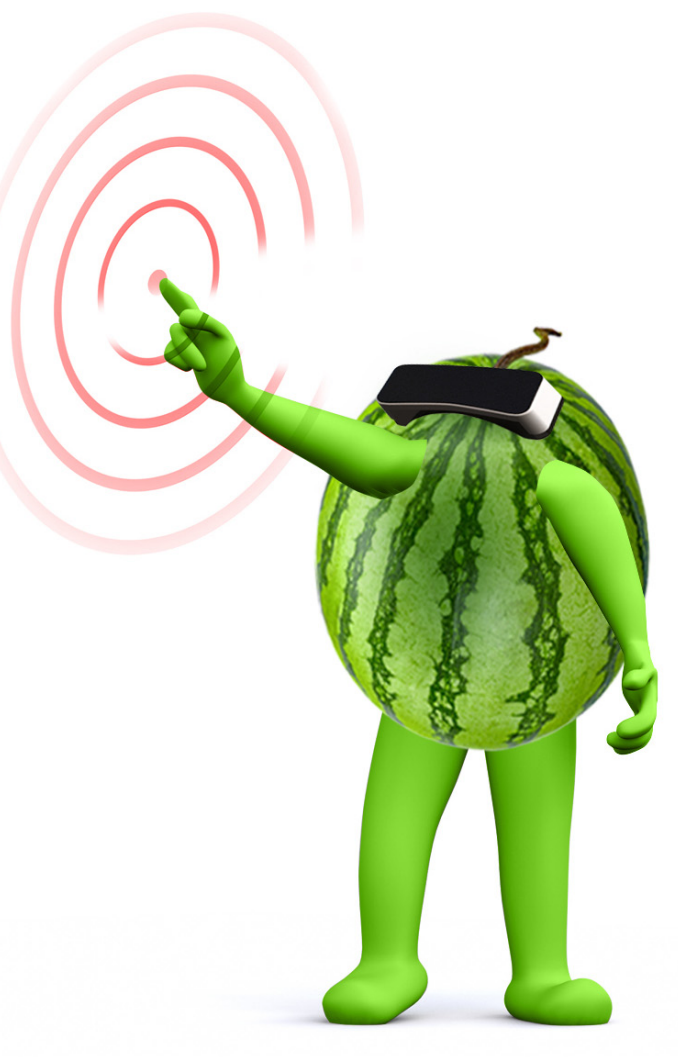

\title{
WILL THE USE OF VIRTUAL REALITY LEAD TO A REVOLUTION IN MARKETING COMMUNICATION?
}




\section{$\$$ sciendo}

\section{WILL THE USE OF VIRTUAL REALITY LEAD TO A REVOLUTION IN MARKETING COMMUNICATION?}

Anna Szymczak, M,Sc.

University of Lodz

annakatarzyna.szymczak@gmail.com

DOI: 10.2478/minib-2019-0043

\section{Summary}

A contemporary consumer is a challenge for marketing specialists. The analysis of the conducted research shows that only a well-constructed marketing message, using new technologies will be a key element of effective marketing communication. There is a growing interest in the use of virtual and augmented reality on the market.

The aim of the work is to analyze the possibilities of using innovative tools, based on virtual and augmented reality in marketing communication. The source basis of the study is available literature on the subject, secondary sources, own analyzes and research and studies carried out by foreign research institutes.

The paper presents the results of authorial research carried out in 2018 using the CAPI method, as well as self-audit of marketing activities using VR and AR based on the SERVQUAL model. The results of the study indicate limited use of VR and AR. It should also be emphasized that these results are not representative, but point to a relationship that is worth exploring on a larger research group.

Keywords: virtual reality, augmented reality, 3D visualization, marketing communication 



\section{Introduction}

A literature review showed that $\mathrm{VR}$ and $\mathrm{AR}$ technologies are relatively rarely used by marketers.

The results of the research presented in the article also prove it. The results of another study indicate that using visual methods it is possible to increase online or mail order sales. As Gartner noted in 2016, virtual reality is one of the most promising technological innovations in business.

The aim of this paper is to analyze the possibility of using innovative tools, based on virtual reality and augmented reality in marketing communication.

The source base of the study is the available literature on the subject, secondary sources, own analyses and research, as well as studies carried out by foreign research institutes. The paper presents the results of own research conducted in 2018 with the CAPI method on a group of 114 respondents. It should be stressed that although the results of the research indicating limited use of $\mathrm{VR}$ and $\mathrm{AR}$ are not representative, they indicate a dependence which is worth exploring in a larger research group.

A self-assessment of marketing activities using $\mathrm{VR}$ and $\mathrm{AR}$ technologies based on the SERVQUAL model was also conducted.

\section{Evolution of research on virtual and augmented reality and definitions}

Research on virtual reality began in the 1960s (Gobbetti and Scateni, 1998). Morton Helig worked on a project called Sensorama in 1957 (Korniejenko, 2018). This construction was supposed to involve all the senses of the viewer during the projection of the image. However, the project has never been widely used due to its high price (Carmigniani \& Furht, 2011).

In the mid-1980s, the creation of different technologies for the development of virtual reality coincided in time to create the first real 
VR systems. The concepts of some of them resemble current VR technology, such as the use of special devices in the form of goggles. It is worth noting, however, that they were larger and heavier than those currently in use.

In the early 1980s, the Massachusetts Institute of Technology developed a limited three-dimensional virtual workspace in which the user could interactively modify $3 \mathrm{D}$ objects spatially corresponding to the position of the hand (Schmandt, 1983).

In 1984 NASA launched the VIVED (Virtual Visual Environment Display) project, followed by the VIEW (Virtual Interactive Environment Workstation) project. As described by Fisher et al. (1986), NASA Ames research aimed to develop a multifunctional, multimodal user interface to facilitate natural interaction with complex operational tasks and to raise awareness of the existence of complex, autonomous integrated systems. The areas of application that NASA Ames focuses on are tele-presence control, surveillance and management of large-scale IT systems and human factors research. Despite the success of the research, virtual reality was not made public until June 6, 1989, when Jaron Lanier, President of VPL, defined the concept of virtual reality (VR), wanting all existing virtual projects to fall into one category. At the beginning of the $1990 \mathrm{~s}$, however, the literature on the subject began to describe this concept in more detail (Reja i Calvo, 2017). Sheerman defined virtual reality as a medium consisting of interactive computer simulations sensing the position of the participant and his actions, replacing or increasing the feedback of one or more senses, offering the participant a sense of being mentally submerged or present in the simulation (in the virtual world). Coates (1992) explains that virtual reality includes electronic simulations of environments experienced by head-mounted glasses and wired clothing that enable the end-user to interact in realistic 3D situations.

Simultaneously with the term virtual reality, the term augmented reality (AG) was introduced by Tom Caudell and David Mizell at Boeing. They developed the first systems for pilot training (Akçayir et al., 2016). This was followed by the use of AR for the training of doctors. At the same time, the entertainment industry was preparing more and more 
computer games using augmented reality. Today, virtual and augmented reality is used not only in the entertainment industry, but also in medicine, engineering and education. In Asian countries, virtual reality is used in education from primary school to university (Huang and Liaw and Lai, 2016).

A characteristic feature of augmented reality is the overlapping of synthetic inscriptions and images on the real image. An example of such action is the HUD system (Head-Up Display) used in airplanes, which on the image seen by the pilot imposes the most important information about flight parameters. Similar solutions are also starting to be applied in cars by displaying information from satellite navigation system on the windscreen.

In 2015 , it was estimated that the number of users of virtual reality could quickly increase, even to 171 million active users in 2018, including 28 million users willing to pay for the offered content (The Farm 51, 2015). At the publication date, no reports summarising the number of participants in 2018 had appeared.

The trend of VR and AR is expected to spread faster than the Internet and smartphones, especially as consumers do not need to invest in very expensive hardware to consume the basic VR content, just add accessories that will turn smartphones into VR devices (Barnes, 2016).

Consumers' quest for new technologies "(...) allows them to see the world around them in a different dimension and to experience things that are not available in real life and have not even been created yet". (Mazurka and Gervautz, 1996). The technology has become a package for providing information to the end user (Kaplan and Mazurek, 2018). The number of existing software is growing rapidly, as is the market entry of companies using new solutions as excellent marketing tools to communicate their advertising content to users (Scatena, Russo and Riva, 2016).

\section{Marketing communication}

Digitalization of communication is a growing phenomenon, reflected in the way marketing communication is planned and 
executed (Mazurka, 2011). Effective use of marketing communication requires not only a very good knowledge of social phenomena and market processes, but also the knowledge of instruments and technologies of information communication. By creating an offer that meets the needs and preferences of buyers and other business partners, the company acquires from the environment, influencing the knowledge, attitudes and behaviors of the addressees, which in turn may shape the demand for its products. Therefore, it can be stated that marketing communication is one of the most important elements determining the establishment and subsequent maintenance of relations between the company and its customers and other market environment entities.

Both marketing theoreticians and practitioners agree that the key condition for the effectiveness of marketing communication is the integration of all its means. All communication activities must be coherent in terms of content, as well as coordinated in time and space. Companies using methods and tools of modern marketing communication are able to quickly interact with consumers (Hajduk, 2016). Two-way, integrated marketing communication is of key importance in creating long-term relationships with customers and other entities in the company's market environment, and thus in the success of the company's relationship marketing concept. Duncan and Moriarty (1998) also stated that business relations cannot be established without communication.

Practitioners emphasize that the period of marketing has come in the perspective of communication, i.e. skillfully predicting the preferences of narrow groups of customers, as well as reaching out to individual customers, while at the same time increasing the care for the effectiveness of marketing undertakings. Kowalska (2007) states that the criterion of success of marketing communication strategy and all marketing activities are no longer assumptions typical for mass marketing, but rather various assumptions of a qualitative nature, constituting a measure of the economic effectiveness of these activities (e.g. return on investment in marketing). 


\section{Use of VR and AR in marketing}

Virtual reality is a relatively new medium offering new possibilities of content communication. The features of virtual reality make it capable of manipulating the sense of time and space being interactive and making the user "control" their experiences. Virtual Reality (VR) is considered one of the most promising technological innovations in business (Gartner, 2016). Due to its affordability, this method has become more accessible to consumers, also drawing marketing attention to a new way of advertising products and brands (Adams, 2016). Virtual reality is used mainly in advertising and also by the owners of promotional stands at various trade fairs. VR's scope of application is increasing regularly, and other examples of its use are given below. Emirates allows its customers to virtually visit the aircraft before buying a ticket (replacing the existing form: photos and videos). The Swedish car manufacturer Volvo offers its customers a virtual test drive with the latest car model. Another Swedish company, Ikea, offers to design its own flat. The customer feels like she/he is in a fully furnished apartment. Bank Millennium postulates to increase the interest rate on the deposit for the use of AR in a mobile phone. The Dior cosmetics company offers a test of the latest make-up trends in AR. The customer gets the impression that she is being painted with cosmetics of her choice and then can admire the effects of the make-up.

Virtual reality can be used in simulators or film materials, and a complementary element can be augmented reality, which combines elements of the real and fictional world. Consumers can use the augmented reality with a smartphone in their daily shopping, e.g. by checking the composition of products, the most popular applications. AR glasses can also be used in tourism, e.g. navigation.

Augmented reality and virtual reality are also used in aviation (for training of air traffic controllers, parachute jumpers and pilots - as an equivalent of expensive simulators, for sales of Airbus aircraft, on-board entertainment), medicine (for training medical students), architecture (for presenting proposed architectural solutions), automotive (displaying 
key information or images e.g. from on-board computer, radio or navigation system on the car windscreen).

The most important aspects that distinguish VR from other methods include: accessibility (every customer with a smartphone and goggles can move to the virtual world. The test drive can be used at an appropriate time, without agreeing to pollute the environment), low costs of designing and operating simulators, attractiveness (the applied solutions attract the attention of customers), lack of barriers (fully engaging the show that brings the viewer directly to the promoted or desired locations).

Various studies in marketing literature show that more vivid and realistic images cause more positive attitudes among consumers (Van Kerrebroeck et al., 2017) and thus increase sales. In recent years, advertising has evolved through technological developments, including innovations such as $3 \mathrm{D}$ product presentations and $360^{\circ}$ turnover. Compared to traditional media, they enable a higher level of interactivity and clarity, as well as visual richness (Choi and Taylor, 2014).

According to a survey conducted by eMarketer in October 2015, 64 percent of respondents indicated that they prefer to see objects in their true size and shape when shopping online. Other surveys show that 36.54 percent of marketers surveyed found VR to be the most exciting digital marketing activity (Virtual Reality Is an Immersive Medium for Marketers, 2016).

VR enables experiences not only anywhere and anytime, but also those that would not be possible in the real world. This may give you a significant advantage over the competition on the market.

The Figure below shows the increase in popularity of search terms "Virtual reality" in Google search engines all over the world.

The presented Table shows that virtual reality was most frequently searched for in December 2016, which was caused by several promotional campaigns, including Coca-Cola, Uber, Ikea, Volvo. 
Figure 1. Virtual reality - popularity according to Google statistics

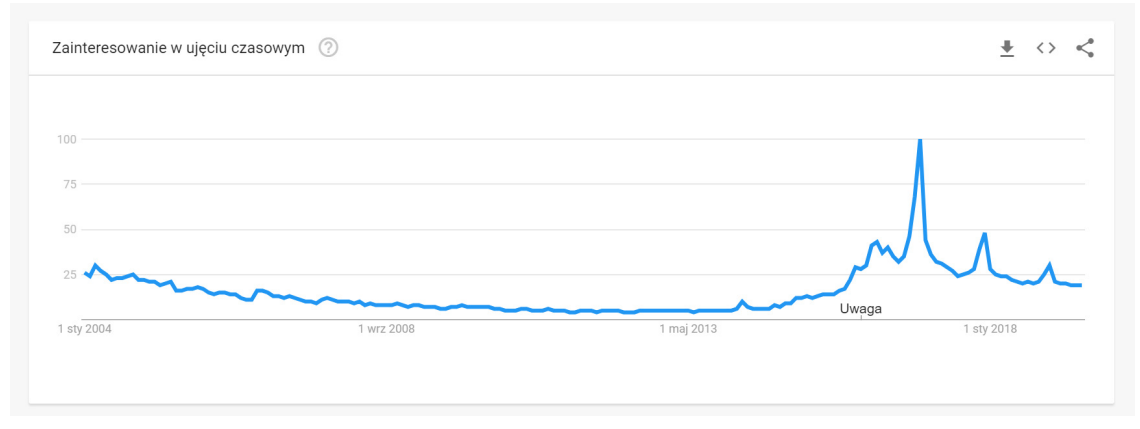

Source: https://trends.google.com/trends/explore?date=all\&q=Virtual\%20Reality

Analysis of the use of VR and AR

in marketing communication in the light of own research

First research - own audit

The own audit was performed in May 2019. It was carried out with the use of accessories changing the Samsung S5 neo smartphone into an environment of virtual and augmented reality. The goggles used for the audit were ISY Virtual Reality Glasses IVR 1000 (in the electronic store for about $60 \mathrm{PLN}$ ). Own audit was performed with the use of SERVQUAL method.

The first examined company was a Swedish car manufacturer Volvo. After installing a dedicated application on a smartphone and configuring the goggles, it was possible to take a test drive in the latest car model. The application worked perfectly, was graphically refined, realistically transferred into the interior of the vehicle. Not all the buttons on the cockpit were interactive. Using the SERVQUAL method, the expected quality was in line with the received quality. 
The Swedish company Ikea was also the next company to be surveyed. In this case, it was also necessary to install a dedicated application. The first attempt to run it turned out to be impossible, rebooting the smartphone solved the problem. When the application was launched, the user moved to a virtual kitchen and became a child of 100 centimetres tall. The application was fully interactive. Summing up, the quality received exceeded the expected quality.

Tables 1 and 2 show the evaluation of the expected and obtained quality of VR and AR. Volvo is labelled "V" and Ikea is labelled "I".

\section{Table 1. Questions included in the VR and AR \\ expected quality assessment questionnaire}

\begin{tabular}{l|l|c|c|c|c}
\hline \multicolumn{1}{c}{ Specification } & $\mathbf{1}$ & $\mathbf{2}$ & $\mathbf{3}$ & $\mathbf{4}$ & $\mathbf{5}$ \\
\hline $\begin{array}{l}\text { 1. } \\
\text { 2. }\end{array}$ & $\begin{array}{l}\text { Access to VR and AR should be easy } \\
\text { If there is a problem with functionality, employees should } \\
\text { immediately provide assistance }\end{array}$ & & $\mathrm{I}$ & $\mathrm{V}$ & \\
3. & $\begin{array}{l}\text { Functionality of the VR and AR should offer } \\
\text { unlimited possibilities } \\
\text { Graphical capabilities of the VR and AR applications/platforms } \\
\text { should be expanded }\end{array}$ & & V/I & I & V \\
\hline
\end{tabular}

Source: own elaboration.

Table 2. Questions included in the questionnaire for the evaluation of the experienced quality of VR and $A R$

\begin{tabular}{|c|c|c|c|c|c|c|}
\hline & Specification & 1 & 2 & $\mathbf{3}$ & 4 & 5 \\
\hline $\begin{array}{l}1 . \\
2 .\end{array}$ & $\begin{array}{l}\text { Access to VR and AR should be easy } \\
\text { If there is a problem with functionality, employees } \\
\text { immediately provided assistance } \\
\text { Functionality of the VR and AR should offer unlimited possibilities } \\
\text { Graphical capabilities of the VR and AR applications/platforms } \\
\text { should be expanded }\end{array}$ & & I & & $\begin{array}{l}\mathrm{V} \\
\mathrm{V}\end{array}$ & $\begin{array}{c}\mathrm{I} \\
\mathrm{V} / \mathrm{I}\end{array}$ \\
\hline
\end{tabular}

Source: own elaboration. 
Then the VR Virtual House in Eódź was visited where other possibilities of virtual reality were tested. The visit to the professional studio was supposed to indicate whether there are any significant differences between the equipment commonly available to consumers and its professional counterpart. The observed changes were, however, insignificant. In the case of programs with extensive graphics, professional hardware (with higher computing capabilities) was the only alternative.

The second study - using VR and AR in marketing communication in the opinion of consumers

The study was conducted in order to verify the popularity of VR and AR. The survey was conducted in the period from September to December 2018 in the form of a CAPI survey on a mobile device. Randomly selected visitors to shopping centres in Łódź (Manufaktura, Galeria Łódzka, Port Łódź, Sukcesja) were invited to participate in the survey. The questionnaire was filled in by 114 people, and according to the survey questionnaire, 62 percent of them were women.

Table 3. Benefits of using VR and AR

\begin{tabular}{l|c|c|c|c}
\hline \multirow{2}{*}{ Benefits of using VR i AR } & \multicolumn{2}{|c|}{$\begin{array}{c}\text { All benefits } \\
\text { (multiple possibilities) }\end{array}$} & \multicolumn{2}{c}{$\begin{array}{c}\text { The most important benefit } \\
\text { (single possibility) }\end{array}$} \\
\hline Visualisation & 44 & $19 \%$ & 13 & $28 \%$ \\
Interaction & 38 & $16 \%$ & 11 & $23 \%$ \\
Impact on imagination & 42 & $18 \%$ & 8 & $17 \%$ \\
Stimulating curiosity & 41 & $17 \%$ & 8 & $17 \%$ \\
Egagement & 24 & $11 \%$ & 4 & $9 \%$ \\
Safety & 20 & $8 \%$ & 1 & $2 \%$ \\
Availability & 17 & $7 \%$ & 1 & $2 \%$ \\
Offer & 10 & $4 \%$ & 1 & $2 \%$ \\
\hline
\end{tabular}

Source: own elaboration. 
Only 40 percent of respondents had contact with virtual reality, while 48 percent of respondents took advantage of augmented reality. Unfortunately, respondents did not use this technology regularly (18\% of respondents in the case of VR and $26 \%$ in the case of AR did so regularly). It should also be noted that only 22 per cent of respondents had accessories used for AR and VR, e.g. special goggles. Respondents were asked to indicate the main advantages of using virtual and augmented reality. Respondents pointed out that being able to move into another dimension is the most important benefit.

The respondents most willingly pointed to the possibility of visualizing products that are difficult to access. The answer appeared in 44 out of 47 respondents. There is no doubt that the companies are only just implementing VR and AR to their marketing activities.

\section{Summary}

Virtual and augmented reality technology is a dynamically developing innovation that affects consumer behaviour and product perception. Research conducted by Kerrebroeck et al. has shown that VR has a positive impact on brand perception and purchase intentions. Virtual presentations can give consumers the opportunity to better explore products such as clothing using technology (Verhagen and Vonkeman and van Dolen, 2016). In the age of modern technology, research focused on the perception of marketing communication materials gives insights into how such activities are conducted. They also confirmed that VR technology can significantly facilitate the presentation of certain market offers in the real estate sector.

Technological innovations laid the foundations for creating a completely new field of communication and content delivery as well as an innovative approach significantly facilitating the flow of information between different market entities.

Other studies show that traditional paper advertising is the weakest means of marketing communication compared to other more advanced 
tools indicating the process of digitisation of marketing. The mission of marketing managers is to put more emphasis on the choice of technologies used in the transmission of marketing messages. As indicated in the research, the use of modern technologies has a positive impact on the impact of marketing messages, and thus translates into a much better perception of the message among potential customers. The applied technologies may constitute a significant support for marketing and sales strategies.

Further research should focus on the implementation of analogous experiments for different types of products, as well as on the analysis of the relationship between the reception of technology, message and offer, and purchase decisions, together with the management implications of using virtual reality in marketing communication strategies and tactics (Grudzewski et al, 2018).

Our own audit showed that the quality of VR and AR offered by Volvo and Ikea covered or exceeded the expected quality. There was also no significant difference in the equipment used in VR and AR.

An authorial survey of 114 respondents showed little experience and knowledge of virtual and augmented reality. When asked about the most important benefit of using VR and $\mathrm{AR}$, respondents were most eager to point to the possibility of visualizing hard-to-reach products. The least frequently chosen answer was the possibility to present the company's offer using VR and AR. This could have been due to the fact that VR and AR technology is not yet sufficiently widespread in Poland.

The analysis of secondary data shows that marketing communication tools, especially VR and AR, can be an effective element in building a competitive advantage. Due to the technological development, it is advisable to repeat the study and constantly monitor the usefulness of these marketing activities. 


\section{Bibliography}

\section{Monographs and articles}

1. Akçayir M., Akçayir G., Pektas H. M., Ocak M. A. (2016). Augmented reality in science laboratories: The effects of augmented reality on university students' laboratory skills and attitudes toward science laboratories, Computers in Human Behavior, No. 57, p. 334-342.

2. Carmigniani J., Furht B. (2011). Augmented reality: An overview, [In:] Furht B. (red.): Handbook of augmented reality, Springer, Nowy Jork.

3. Coates, G. (1992). Program from invisible site - a virtual shop, a multimedia performance. San Francisco, CA: Performance Works.

4. Choi Y. K., Taylor, C. R. (2014). How do 3-dimensional images promote products on the Internet? Journal of Business Research, 67, 2164-2170.

5. Duncan T., Moriarty S. E. (1998). A Communications-Based Marketing Model for Managing Relationships. Journal of Marketing, Vol. 62, No. 2.

6. Fisher S. S., McGreevy M., Humphries J., Robinett W. (1986). Virtual environment display system. In Proc. 1986 ACM Workshop on Interactive 3D Graphics (Chapel Hill, NC, Oct. 1986), p. 77-87.

7. Gobbetti E., Scateni R. (1998). Virtual reality: Past, present and future, Studies in health technology and informatics, 02/98.

8. Grudzewski F., Awdziej M., Mazurek G., Piotrowska K. (2018). Virtual reality in marketing communication - the impact on the message, technology and offer perception - empirical study. Economics and Business Review, Vol. 4 (18), No. 3, 2018: 36-50.

9. Hajduk G. (2016). Challenges for marketing communications in the digital age. [w:] G. Mazurek \& J. Tkaczyk (Eds.), The impact of the digital world on management and marketing (pp. 183-195). Warszawa: Poltext.

10. Huang H., Liaw S., Lai C. (2016). Exploring learner acceptance of the use of virtual reality in medical education. Interactive Learning Environments, No. 24 (1), 2016, p. 3-19.

11. Kaplan, A. \& Mazurek, G. (2018). Social media: state of the art and research agenda. [w:] B. Mierzejewska, J. Jung, \& A., Albarran, (Ed.), 2nd handbook of media management and economics. London, United Kingdom: Routledge.

12. Korniejenko K. (2018). Wykorzystanie wirtualnej rzeczywistości jako nowoczesnego narzędzia wsparcia w kształceniu inżynierów. Zeszyty Naukowe Wydziatu Elektrotechniki i Automatyki Politechniki Gdańskiej No. 58/2018, p. 37-40.

13. Kowalska M. (2007) Zyskać przewagę. Zintegrowana komunikacja w nowoczesnym marketingu. wyd. A. Marszałek, Toruń.

14. Mazurek, G. (2011). Informacja w wirtualnym środowisku a rozwój społeczeństwa informacyjnego. Zeszyty Naukowe Uniwersytetu Szczecinskiego. Ekonomiczne Problemy Ustug, 186-194.

15. Mazuryk, T., Gervautz, M. (1996). Virtual Reality: history, applications, technology and future, technical report. Vienna: Institute of Computer Graphics, Vienna University of Technology.

16. Raja V., Calvo P. (2017). Augmented reality: An ecological blend. Cognitive Systems Research, No. 42, 2017, p. 58-72. 
17. Scatena S., Russo G. N., Riva G. (2016). Virtual Reality vs television vs web exposure: the impact on brand experience. A preliminary study. Annual Review of Cybertherapy and Telemedicine, 14, 211-214.

18. Schmandt C. (1983). Interactive three-dimensional computer space. Proc. SPIE Int. Soc. Opt. Eng. 367, p. 155-159.

19. Wrzosek W. (2012). Strategie marketingowe. PWE, Warszawa.

20. Van Kerrebroeck H., Brengman M., Willems K. (2017). When brands come to life: experimental research on the vividness effect of Virtual Reality in transformational marketing communications. Virtual Reality, 21(4), 177-191.

21. Verhagen T., Vonkeman C., van Dolen W. (2016). Making online products more tangible: the effect of product presentation formats on product evaluations. Cyberpsychology. Behavior, and Social Networking, 19(7), 460-464.

Referaty, raporty $i$ inne materiaty

1. Adams, R. L. (2016). Five ways virtual reality will change the world. Forbes. https:/www.forbes.com/sites/robertadams/2016/10/17/5-ways-virtual-reality-will-change-the-world/\#311e2cc2b018 (25.06.2019).

2. Barnes, S. (2016). Understanding virtual reality in marketing: nature, implications and potential. doi: https://dx.doi.org/10.2139/ssrn.2909100 (22.06.2019).

3. Gartner. (2016). Gartner's 2016 hype cycle for emerging technologies identifies three key trends that organizations must track to gain competitive advantage. https://www.gartner.com/newsroom/id/3412017 (22.06.2019).

4. The Farm 51. (2015). VR market report. http://thefarm51.com/ripress/VR_market_report_2015_The_Farm51.pdf (24.06.2019).

5. Virtual Reality Is an Immersive Medium for Marketers. https://www.emarketer.com/Article/Virtual-Reality-Immersive-Medium-Marketers/1013526 (22.07.2019).

\section{Webography}

1. https:/www.volvocars.com/us/about/our-points-of-pride/google-cardboard (27.06.2019)

2. https://www.ikea.com/ms/pl_PL/this-is-ikea/ikea-highlights/Virtual-reality/index. html (26.06.2019)

3. https://marketinglink.pl/wirtualna-rzeczywistosc-dlaczego-warto-sie-tym-przejmowac/ (26.06.2019)

4. https://pclab.pl/art69208.html (22.06.2019)

5. https://epicvr.pl/pl/skuteczne-kampanie-vr/ (25.06.2019)

6. https://www.pcworld.pl/ranking/8-branz-ktore-zmieni-VR, 407042.html (23.06.2019) 
Anna Szymczak, M.Sc., University of Lodz, Poland - Ph.D. Candidate in Marketing Department, Faculty of Management, University of Lodz. Since childhood, fascination with civil aviation. Her interests are connected with scientific and professional work. She teaches in Marketing Fundamentals. Awarded with distinction for activities for and for the good of the University of Lodz. Graduate of Postgraduate Studies - Management and financing in the air transport sector at the Warsaw School of Economics. Member of Board of The National Representation of PhD Candidates. 